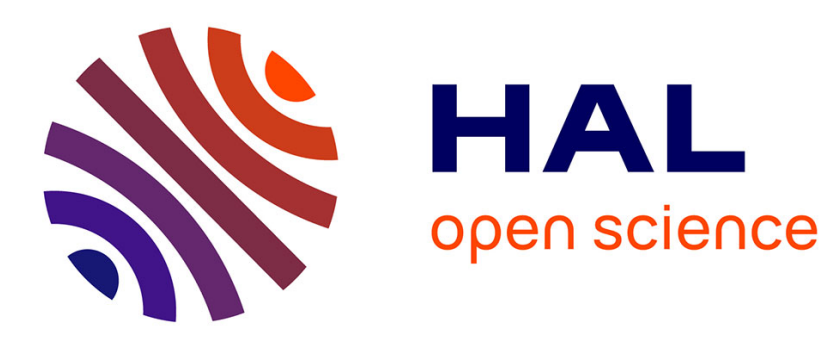

\title{
PHOTOREFRACTIVE GRATING BUILD-UP BY A 28-ps LIGHT PULSE IN BSO
}

\author{
Jean-Michel Jonathan, Gérald Roosen, P. Roussignol
}

\section{To cite this version:}

Jean-Michel Jonathan, Gérald Roosen, P. Roussignol. PHOTOREFRACTIVE GRATING BUILD-UP BY A 28-ps LIGHT PULSE IN BSO. Journal de Physique Colloques, 1988, 49 (C2), pp.C2-267-C2-270. 10.1051/jphyscol:1988263 . jpa-00227680

\section{HAL Id: jpa-00227680 https://hal.science/jpa-00227680}

Submitted on 1 Jan 1988

HAL is a multi-disciplinary open access archive for the deposit and dissemination of scientific research documents, whether they are published or not. The documents may come from teaching and research institutions in France or abroad, or from public or private research centers.
L'archive ouverte pluridisciplinaire HAL, est destinée au dépôt et à la diffusion de documents scientifiques de niveau recherche, publiés ou non, émanant des établissements d'enseignement et de recherche français ou étrangers, des laboratoires publics ou privés. 


\title{
PHOTOREFRACTIVE GRATING BUILD-UP BY A 28-ps LIGHT PULSE IN BSO
}

\author{
J.M.C. JONATHAN, G. ROOSEN and P. ROUSSIGNOL* \\ Institut d'optique Théorique et Appliquée, CNRS UA-14, Bât. 503, \\ $B P$ 43, F-91406 orsay Cedex, France \\ "Laboratoire d'optique Quantique du CNRS, Ecole Polytechnique. \\ F-91128 Palaiseau Cedex, France
}

Résumé : Le modele de transfert de charge dans I effet photoréfractif prévoit sa construction par une impulsion picoseconde. Nous en donnons une vérification expérimentale illustrant le rôle du phénomène de diffusion, dans des cristaux tels que le BSo, où la période du réseau induit peut être inférieure à la longueur de điffusion des porteurs.

\begin{abstract}
The band transport model predicts the build-up of the photorefractive efffect by a picosecond pulse. An experiment has been performed the emphasizes the unique role of the diffusion process : In crystals such as BSO, where the period of the photorefractive grating may be made smaller than the diffusion length of the charge carriers.
\end{abstract}

\section{I - INTRODUCTION}

The photorefractive effect has been described in a variety of crystals. Experimentation under C.W. illumination confirms the band transport model, described by $N$. Kukhtarev : through the redistribution of photoexcited charge carriers, an electrostatic field is induced that modulates the refractive index via the electrooptic effect /1/. Short pulses /2-6/ illumination have been recently experimented, illustrating the build up of the photorefractive effect during the laser pilse. We examine here the speed of the effect when induced by laser pulses shorter than the recombination time of the charge carriers. Predictions of the model and, experimental verifications in the case of BSO $/ 7 /$, are presented.

\section{II - THEORETICAL CONSIDERATIONS}

The basic equations for the photorefractive effect have been fully described and studied by many authors. Many predictions have been verified and used for the characterization of photorefractive crystals. The effect was then observed in its so-called $C . W$. illumination regime (life time $\tau_{R}$ of the charge carriers, much smaller than the duration of the illumination and density of free charges neglegible compared to that of trapping centers). The space charge then occurs from repeated excitation, drift or diffusion, and recombination of the carriers. The recombination time $\tau_{R}$ appears thus as a basic limitation to the increase with iliumination, of the speed of the photorefractive effect.

A different behavior is predicted when illumination is shorter than the recombination time. Without applied electric field, the photorefractive effect then builds-up after the end of the light pulses /8/, either by recombination or by diffusion of the carriers, depending on the relative values of the recombination time $\tau_{R}$ and the diffusion time : $\tau_{D}=\frac{e}{k_{B} T} \frac{1}{\mu k_{g}^{2}}$ (1)

( $\mu$ : carrier mobility, $\mathbf{k}_{g}$ : grating wave number). When the pulse duration $\tau_{2}$ is much shorter than both $\tau_{R}$ and $\tau_{p}$, a sinusoidal illumination of modulation $m$ leads to a spatial distribution of carriers $n(x)=n_{0}+n_{1} \cos k_{a} x$ governed by the rate equation alone. $n_{0}$ and $n_{1}$ are determined by the incident energy, the 
modulation $m$, and the density of filled traps $N_{0}-N_{0}^{+}$. Such an illumination leaves two superimposed compensating charge distributions (free carriers and fixed ions). Efficient photorefractive effect may be built if diffusion is much faster than recombination. The modulation $n_{1} / n_{0}$ of the carriers distribution is then washed out, leaving the ion grating, and a subsequent space charge field. A steady state is reached when the diffusion of charges is balanced by their drift in the induced field. The ratio between $\tau_{R}$ and $\tau_{D}$ may be written as :

$$
\frac{\tau_{d}}{\tau_{r}}=\left(\frac{1}{L \cdot k_{g}}\right)^{2} \text { with } L=\sqrt{\mu, \tau_{R} \frac{k_{B} T}{C}}
$$

where $L$ is the diffusion length of the charge carriers. The described process is then possible in crystals where the grating spacing may be made smaller than $2 \pi L$. For BSo, $(2 \mu \mathrm{m} \leqslant L \leqslant 8 \mu \mathrm{m}) / 9 /, \tau_{d} / \tau_{\mathrm{p}}$ will be smaller than $4 \%$ for a grating period of $2.5 \mathrm{\mu m}$. For $\mathrm{BaTiO}_{3}$, L is smaller than $10 \mathrm{~nm}$, impeding the build-up of a photorefractive grating by pure diffusion.

We performed the numerical integration of the basic Kukhtarev's equations. The only approximation made is that of a low modulation $m$, in order to linearize the equations as usually done. Times are expressed in units of recombination time in the dark, charge densities in units of $N_{D}^{+}$in the dark. Fluences $I_{0}$ are normalized as $I_{0}=s I_{0} \tau_{R}$, whith a photoexcitation cross section s estimated to $10^{-5} \mathrm{~m}^{2} \mathrm{~J}^{-1} / 10 / . \tau_{\mathrm{p}} / \tau_{\mathrm{r}}$ was taken equal to $1 \%$ from a grating period of $2.5 \mu \mathrm{m}$ and a diffusion length of $3.4 \mu \mathrm{m}$ (determined in the same sample from $\mathrm{C} . \mathrm{W}$. regime diffraction experiments). The light pulse was assumed to be much smaller than $\tau_{D}$. Figure 1-b shows the resulting plot, versus time, of the square modulus of the space charge field, along with that of the charge densities $(1-a)$ : the decay of $n_{0}$ is governed by recombination while that of $n_{1} / n_{0}$ is due to diffusion and follows the rise of the space charge field. Further recombination is of some influence only in the case of higher pulse energy. The density of free charges remains strongly modulated when the space charge field balances the diffusion. Later recombination causes a non negligeable decay of the effect (Figure 1-c).

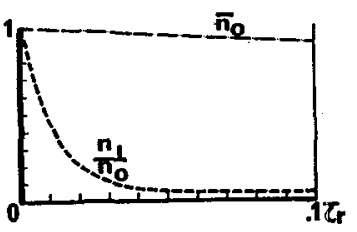

a

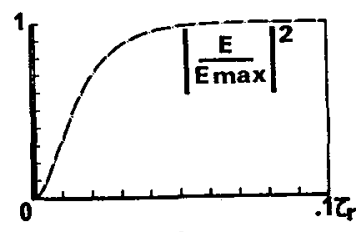

b
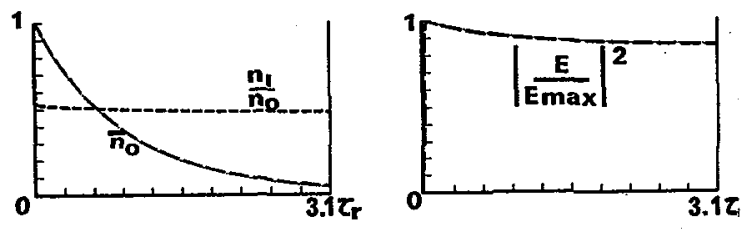

C

Figure 1 : a) decay of the carrier density $n_{0}$, and modulation $\frac{n_{1}}{n_{0}}$

b) build-up of the squared space charge field, c) effect of later recombination in the case of higher energy pulses.

\section{III - EXPERIMENTAL EVIDENCE}

Experimentation was performed on an undoped n-BSO sample from sumitomo, using the arrangement of figure 2. single pulses are extracted from a mode-locked YAG Laser, using a Pockels cell. $28 \mathrm{ps}, 0,5 \mathrm{~mJ}$ pulses at $0,53 \mu \mathrm{m}$ are then obtained by amplification and frequency doubling with a repetition rate of $2 \mathrm{~Hz}$. Three beams $S_{1}, S_{2}$ are $R$ are made. $S_{1}$ and $R$ are counter 
propagating while the angle between $S_{2}$ and $S_{1}$ is made equal to $13^{\circ}$. Two grating with $2.3 \mu \mathrm{m}$ and $0.3 \mu \mathrm{m}$ spacings are thus written in B.S.O.. Low modulation $\mathrm{m}$ is obtained by making $\mathrm{S}_{2} 1 \%$ of $\mathrm{S}_{1}$ and $\mathrm{R}$ in energy. The diffracted signal, extracted by beam splitter BS3, is detected on a PMT. The diffraction efficiency is obtained by comparison with the signal from a reference P.I.N. photodiode.

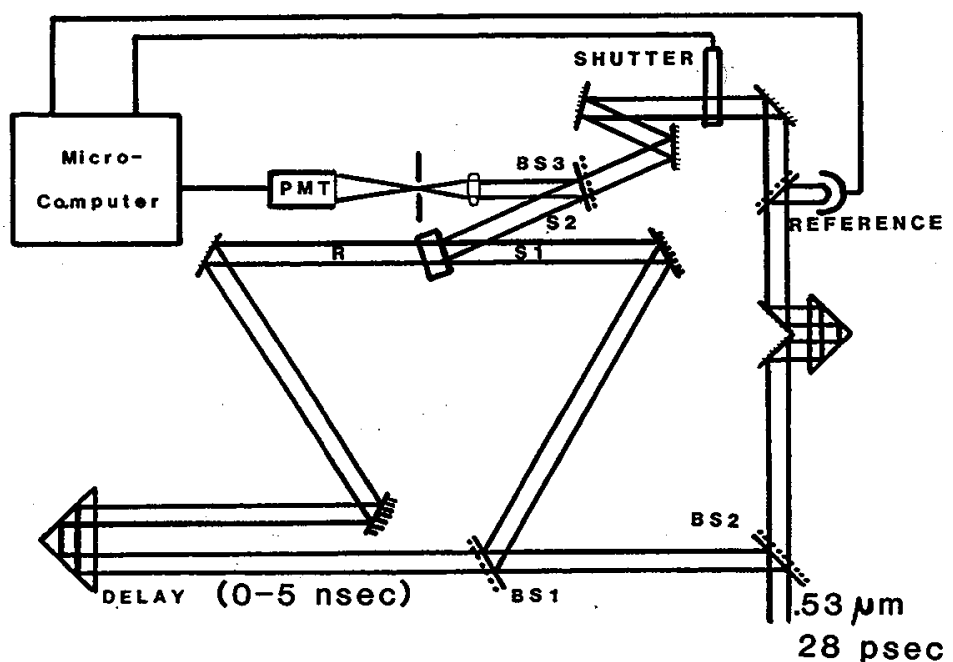

Figure 2: Experimental set-up

Single $S_{1}$ and $S_{2}$ pulses write a grating whose diffraction efficiency is monitored by a single $R$ pulse which may be delayed from zero to five nanoseconds. The signals from the P.M.T. and the photodiode are digitized and stored. A shutter then blocks $S_{2}$ and the recorded grating is erased by as many $S_{1}$ and $R$ pulses as needed, before changing the delay. Each point on figure 3 was averaged from twenty such measurements. The sharp peak first observed corresponds to the situation of real D.F.W.M, previously observed /11/ and described in terms of kerr effect/12/. Later the build-up of a grating is observed with a rise time of $4 \mathrm{~ns}$. This grating persists in the dark and could be tested a few seconds after the writing pulses. This is a good indication of its photorefractive origin. All attempts to observe the $0.3 \mu \mathrm{grating}$ failed.

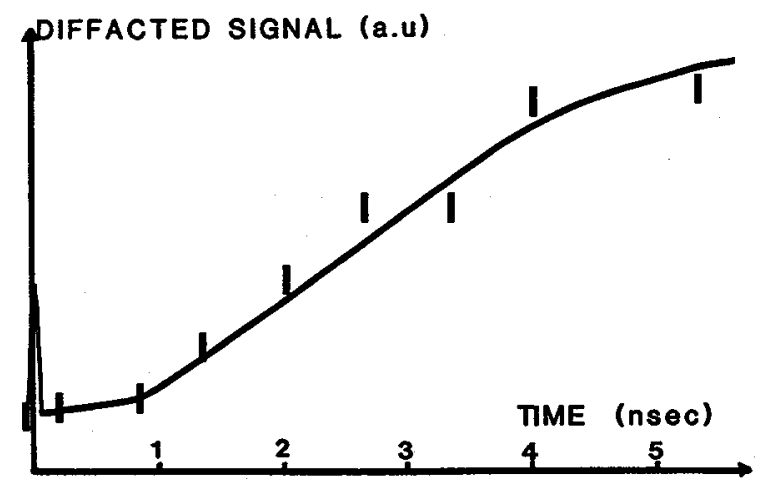

Figure 3 : Experimental results : time evolution of the diffraction efficiency, after the laser pulse. 
As expected, a very low value of the diffraction efficiency (5.10-8) is found in fairly good agreement with a space charge field of a few $V / c m$ as predicted by the simulation for low writing pulses energy.

\section{CONCLUSION}

The strength of the photorefractive effect is then governed by a site density $\left(N_{D}-N_{D}^{+}\right)$which, in most crystals, is much bigger than that its empty portion $\mathrm{N}_{\mathrm{D}}^{+}$limiting the effect in the C.W. case. Further more, the effect may be faster than the recombination time in any material in which the diffusion time may be made faster than the curvers life time.

The authors wish to thank D. Ricard for helpfull discussions.

\section{REFERENCES}

/1/ N.V. Kukhtarev, V.B. Markov, S.G. Odulov, M.s. Soskin, V.L. Vinetskii, Ferroelect., 22. 949, 1979.

/2/ C.T. Chen, D.M. Kim, D. Von der Linde, IEEE, Journ. Quantum Elect., QE-16, 126,1980 .

/3/ L.K. Lam, T.Y. Chang, J. Feinberg, R.W. Hellwarth, Opt. Lett., 6, 475, 1981.

/4/ G. Le Saux, G. Roosen, A. Brun, Opt. Comm., 56, 374, 1986 and $\underline{58}, 238$, 1986 .

/5/ G.C. Valley, A.L. Smirl, M.B. Klein, K. Bohnert, T.F. Boggess, Opt. Lett. , 11, 647, 1986.

/6/ A.L. Smirl, G.C. Valley and R.A. Mullen, K. Bohnert, C.D. Mire and T.F. Boggess, Optics Letters, 12, 7, (1987), p. 501.

/7/ J.M.C. Jonathan, G. Roosen and Ph. Roussignol, Optics Letters, Mars 88, Vol. 13, to be published.

/8/ G.C. Valley, IEEE Journal of Quantum Electronics, QE-19, 11, 1983, p. 1635 .

/9/ G. Pauliat, J.M.C. Jonathan, M. Allain, J.C. Launay, G. Roosen, Opt. Comm. $59,2666,1986$.

/10/ M. Peltier, F. Micheron, J. Appl. Phys., 48, 3683, 1977

/11/ J.L. Ferrier, J. Gazengel, X. Nguyen Phu, G. Rivoir, Opt. Comm., 58, 343,1986 .

/12/ A. Brun, G. Le Saux, G. Roger, F. Salin, "Photorefractive Bso response under femtosecond illumination", CLEO Baltimore, may 1987. 